\title{
Breaking the Basic-Clinical Barrier in an Integrated Medical Education Curriculum; Experience of Al-Baha University, Saudi Arabia
}

\author{
Emad A. Koshak ${ }^{1,2^{*}}$, Adel Abdelaziz ${ }^{3,4}$
}

${ }^{1}$ Department of Internal Medicine, Allergy and Clinical Immunology, Faculty of Medicine, King Abdulaziz University, Jeddah, Saudi Arabia. 'Department of Internal Medicine, Faculty of Medicine, Al-Baha University, Al-Baha, Saudi Arabia. ${ }^{3}$ Medical Education Development Unit, Faculty of Medicine, Al-Baha University, Al-Baha, Saudi Arabia. ${ }^{4}$ Department of Medical Education, Faculty of Medicine, Suez Canal University, Ismailia, Egypt.

\begin{abstract}
The revolution of integration in medical education has come with what was neither expected nor accepted in the past. Many barriers, like those among disciplines, have been vanished but one still exists. This existing one is the basic-clinical barrier. Consequences of this clearly appear in the registration and assessment rules that regulate the passage of students across this barrier. For example, students who fail in one single basic-science module or discipline are forced to stay at home for a full academic year to be re-examined in this module or discipline. After passing this module, they are allowed to register in the clinical phase. In light of this injustice that may affect a proportion of students, it was necessary to reform these stiff rules parallel to the reform in curricula.
\end{abstract}

Keywords: integration, basic sciences, clinical disciplines, registration rules

\section{Introduction}

Flexner's report of 1910 on medical education in North America transformed the approach to teaching/training of students from just preceptorship/ apprenticeship to didactic teaching, experimentation and research. This gave birth to what is today referred to as the traditional curriculum ${ }^{(1)}$. With the introduction of new learning methodologies such as Problem-based Learning ( $\mathrm{PBL}$ ) and early exposure to patients, basic sciences learning has become more integrated with clinical guidance. Accordingly, aspects of clinical learning and early clinical experience are brought back into the early undergraduate years. Likewise, basic science subjects are represented explicitly in the curriculum within the clinical environments during all the years of undergraduate education. Hence, the virtual division between the basic sciences and the clinical years has been eroded ${ }^{(2)}$. Integration in modern medical education has abandoned the traditional discipline based discreet segmentation and isolation of teaching and learning activities within concert silos. Integration seeks to break down the barriers between subject areas in order to provide students with better learning opportunities that will facilitate the development of knowledge that is relevant and meaningful to clinical practice. Additionally, this knowledge is deep, retrievable, amenable to alteration, capable of updating and development as a part of an ongoing process of lifelong learning. In- 
tegration of the curriculum promotes a holistic and cross discipline approach to patients and their problems. It can also help promote learning in context ${ }^{(3)}$. The integration revolution has changed the curriculum continuum from a rectangle divided into two squares, with a horizontal sharp divide in between, to a rectangle divided into two triangles with a sloping indistinct divide inbetween (Figure 1).

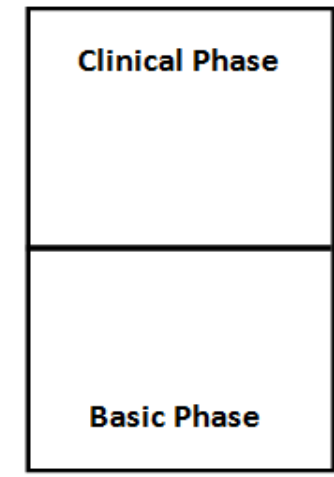

Traditional Curriculum
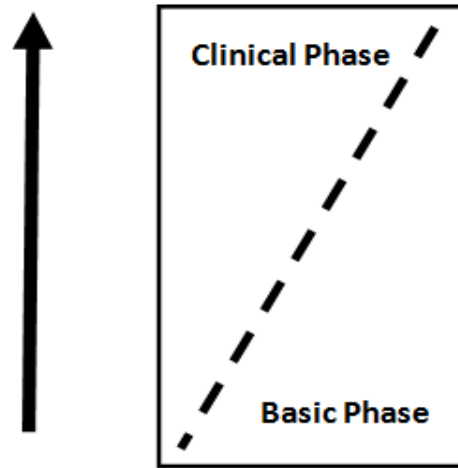

Integrated Curriculum

Figure 1: The basic-clinical barrier in traditional and integrated curricula

Despite this dramatic shift in the internal organization of the curriculum continuum, as a result of integration, an efficacious shadow of the divide between the basic and clinical years still exists. Traditionally, most of the study and examination policies or regulations of medical programs affirmed that in order to go across this barrier and to be able to register for clinical year's rotations, medical students must have passed all the basic sciences modules. These regulations have embedded this virtual barrier between the basic and clinical years and prevented students to pass from phase to another even in case of failure in one module or discipline. Defenders justify these stiff regulations as to maintain quality and standard of students throughout the clinical years. This virtual barrier seemed incompatible with the philosophy, principles, and ultimate goals of integration and has lead to multiple deleterious psychological effects on a broad cross-section of students, those who will have to stay at home for one academic year until passing the failed basic-science disciplines or modules. Al-Baha University Faculty of Medicine (ABUFM) is a new medical college founded in 2008 in the south west of Saudi Arabia. The undergraduate curriculum of ABUFM was designed as nearly as an integrated one quantum. Through means of horizontal and vertical integration, most of the barriers have been removed including the one between the basic and clinical years. Integration has necessitated early introduction of clinical themes that have been addressed through a variety of teaching/ learning methodologies as problem-based learning (PBL), community-based education, clinical-skills training and site visits to different specialized health-service outlets ${ }^{(4)}$. 


\section{Problem statement}

According to the regulations stated in the bylaws, students who fail in one module in the basic sciences phase had to stay for a full academic year to re-study and be reassessed as either competent or not in this module. Those students were not allowed to register for any of the clinical phase modules if they have not finished the study of the failed basic sciences module. These regulations were seen inconsistent with the revolution in content organization and teaching/learning methodologies adopted by ABUFM. Accordingly, a parallel revolution in the regulations of course registration and assessment was indicated.

\section{Applied solution}

After a series of meetings, hearings and negotiations at the local faculty and university levels, a set of organizing rules has been suggested. According to these new regulations, students who fail in no more than two basic-science modules are allowed to register for the first clinical year. This is conditioned by the fact that failed modules are not major prerequisites for other clinical modules. Accordingly, these students can register for the clinical phase and in the meantime reset for the examination of the failed modules within regular time of assessment of these modules (Fig 2).

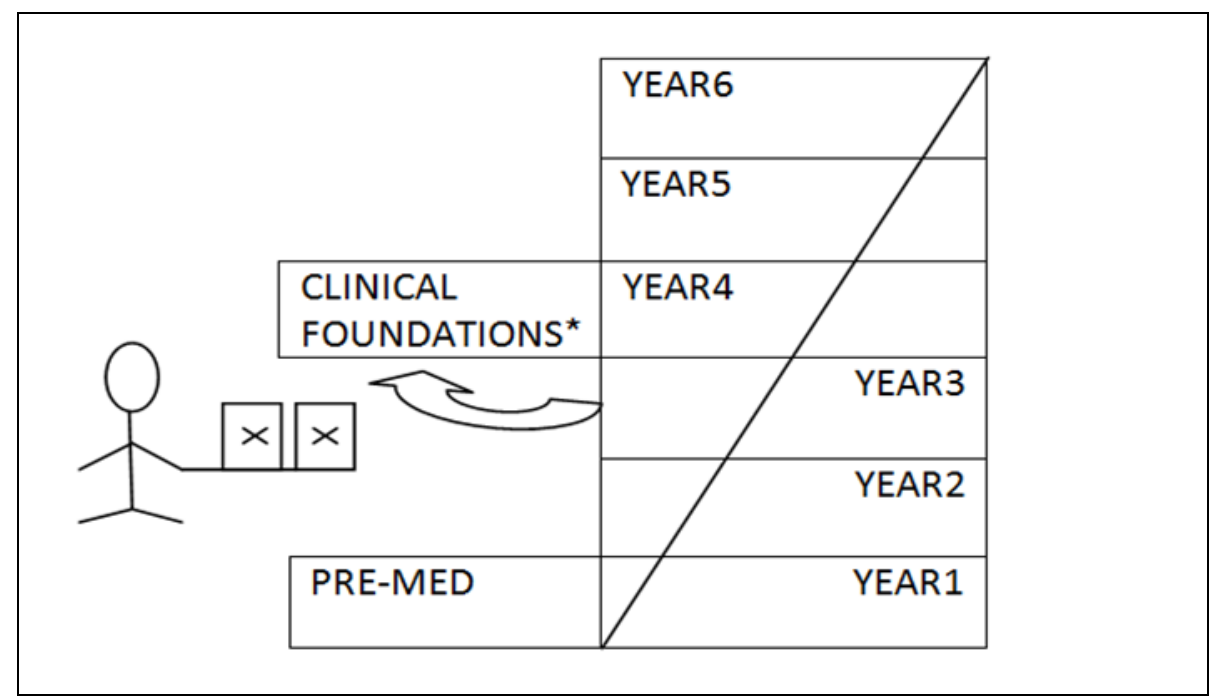

Figure 2: Recommended solution to break the basic-clinical barrier. After year 3, students who fail in one to two basic sciences modules are allowed to register in year 4 , at least in the clinical foundation modules or other modules their prerequisites are fulfilled. (*A group of introductory modules to prepare students before their clinical rotations i.e. Communication skills and history taking; Laboratory medicine and Radiology)

\section{Results and lessons learnt}

After three years of experience, before and after recommending these solutions, the majority of our failed students will no long er be forced to stay at home for restudying one or two basic sciences modules. Targeted students are safe from undesirable edu- cational, psychological, and social sequels consequential to the old rules. Satisfaction of students and faculty staff with the recommended rules are evident through means of program evaluation. When it was thought about modifying the rules to be more flexible and in the interest of students, resistance to change emerged and 
almost thwarted the attempt in its cradle. Now this resistance is unjustified.

\section{References}

1. Student handbook of College of Medicine at King Saud University. 2010; 20-21 http://medicine.ksu.edu.sa.

2. Bradley P, Mattick K. Integration of basic and clinical sciences. AMEE 2008.

3. McKimm J. Current trends in undergraduate medical education: program and curriculum design. Samoa Medical Journal, 2010;2 (1) 40-48.

4. Abdelaziz A. Koshak E. Triangular model integrating clinical teaching and assessment. Adv Med Educ Pract. 2014; 5: 61-64. 